"Calisto zangis Fabr."

"Thecla io Mss. City Park, rare. On Cammomilla."

"Thecla ixion" Fabr.

Lists of moths are also given under "VESPeridae, Phalaenidae and Tineeadae." A list of nondescripts is given which includes thirteen butterflies and sixty-one moths. There have been very few collectors in the locality and I am quite prepared to believe the above mentioned species were found. Species new to our fauna are constantly being recorded from Florida and Texas which have been described from further south. Mrs. Slosson has recently caught a number of species in Southern Florida hitherto only known from the Antilles. Henry Skinner.

\section{NOTES ON EPHYRA PENDULINARIA.}

THE following notes were made nearly forty years ago for a study of the insects of sweet-fern (Comptonia) which I may possibly still be able to complete.

The caterpillar was first observed Aug. 22, 1859, at South Windsor, Conn., and the following description taken :

Color, green; head rust-red with yellowish streaks, and a few scattering hairs; frontal triangle whitish; head appendages except tip of mandibles which are black, white; eyes partly black and partly rust-red. Terminal segment and prolegs roseate spotted with faint green, with a green stripe down hindmost prolegs; body with ten or twelve rows of dots, or continually interrupted lines of a fainter green above, about as many beneath, taking up half the space; stigmatal line very slightly and irregularly pinched. Three rows of short, very fine black hairs on each segment transversely, the center row having but half as many as either of the others, which have but ten hairs in a row, equally above and below; the central row seems to be irregular, and wanting on some segments; legs whitish with a few hairs on them. Length $+\frac{3}{4}$ in; breadth $-\frac{1}{16}$ in.

The thoracic segments and basal joints of legs so contractile that the caterpillar can put all three pairs together on the jaws, with scarcely a bend in the body, and when he does so these segments are so swollen as to give a clubbed look to the caterpillar. When moving, it swings its body sideways (standing on its prolegs) like a pendulum for a while, and then with great tremulousness and frequently touching the surface, goes on. In eating, it cuts deep holes in the leaf, eating at the edge, eating backwards very voraciously for about one-eighth of an inch; then beginning again where it started it goes over the bitten space eating deeper and deeper till the whole is sometimes deeper than wide; it is fond of placing its prolegs on the end of a branch and looking out upon the outer world. It will spin a thread; it often will stand upon the midrib with its prolegs and curving its body, place its legs a little way above the surface, and here remain a long while, looking like a kangaroo ready to leap.

It went to the under side of an oak leaf in its tumbler on Aug. 26, and began spinning, attaching itself by a fine silk circle to the terminal prolegs, and fastened a thread around one of its segments after the manner of butterflies; changed the same day to a chrysalis, throwing the larval skin entirely away.

Chrysalis light green, a black stripe broken twice toward the end on each side, along the hinder margin of the wing. Two protuberances, one at the base of each wing, white, brownish at base; tail-piece almost colorless, tip red. Abdominal segments of a lighter color than the rest, with dots of a lighter tint; anterior half of each abdominal segment punctate, posterior half minutely striate; a thread crosses the body upon which it rests suspended; the thread splits into two at the ends, being fastened at four points; the back is slightly roofed on thoracic segments; the tail-piece is immersed in a silken mass, by which the body is retained in position; head end of the body flat and as if truncate; two projections like warts at base of each wing; the head is square, and the breast flattened; the sides of the body half way down 
the wings quite straight, then it has a little inward curve to the end of the wing, tapering to the tip which is pointed; the outline of the back has an inward curve to a point about two-thirds way down the wing; the tip of wings is on the fourth abdominal segment which they almost cover.

Dec. 9. The chrysalis has turned itself around, and a change has occurred within a few days, for now, instead of green, which it was a week ago, the whole chrysalis is of a satin color and has a little of the satin lustre; the color is uniform throughout; the posterior border of the fourth to sixth abdominal segments are dull golden; the spiracles are reddish. An Ichneumon fly emerged about the middle or end of December.

Specimens were next found at Princeton, Mass., July $1_{5}, 186 \mathrm{I}$, and the following description of the caterpillar taken: Light green with longitudinal white lines, and dotted with white spots. A dorsal and three subdorsal lines; the dorsal straight, but the others broken and irregular, the stigmatal edge wrinkled, the white spots irregularly scattered. Body beneath with the white lines interrupted; the last segment with the anal prolegs and tip of the first pair of prolegs slightly reddish; thoracic legs pale greenish, black at the tips; a few scattered hairs on the body. Head faint reddish, marbled with whitish, with two white stripes. Length four-tenths of an inch; greatest breadth one-twelfth of an inch.

On the night of the $15^{\text {th }}$ it had taken to the top of the box in which it was enclosed, and had slung itself in a thread which crossed the body between the sixth and seventh segments, [ 2-3 abdominal segments ] and had closed its anal prolegs tightly in a mass of silk spun at this point; it now remained motionless, the front part of the body hunched with head bent toward the legs which are gathered closely together. It changed entirely to a chrysalis on July $\mathrm{I} 7$, The disk of the wing, toward the tip, became very pale on July $25^{\text {th }}$; the legs began to darken, as well as the eyes by July 27 ; wings all darkened on morning of the 28th, and emerged during the day.

Another caterpillar found at Princeton July 15 , and probably an earlier stage of this species was light greenish with a reddish tinge above, with very faintly indicated lighter and darker bands; beneath and upon the lower portions of the sides, the green is of a yellowish tint; the reddish tint of the back is deepest on the thoracic and last three segments; there are a very few scattered, very short hairs over the body. The head is of a little deeper red, mottled with lighter, its posterior edge is black on the sides; the triangular spot is lighter, and the edge of the labrum and some parts of the mouth darker. The legs are dirty with darker tips; the prolegs are like the segments which have them. Length $\frac{3}{10}$ of an inch.

Later, again at Princeton, Aug. 24, 186r I found another specimen in general aspect very much resembling the older specimen from Princeton already described, the coloration only being different. It was exceedingly dark green, almost black upon the dorsal and lateral surfaces; streaked on dorsal surface with yellowish just as in the normal type; streaked heavily on lateral surfaces with golden yellow, after the same style as in the other; beneath, the outer portions are brownish, and the inner dirty greenish yellow, all streaked with white longitudinally. Prolegs pale greenish, legs pale yellowish green, dotted with black. Head much as in the first, rust red streaked and dotted with yellowish white; antennae. and labrum as there; black dots of body apparently the same as there, though the general color makes it difficult to distinguish them. Size as before. It changed to a chrysalis on Sept. I2.

On Aug. 12, I found at Princeton a caterpillar just about to turn to chrysalis; it was fastened to the midrib of a leaf of Comptonia near the middle, with the threads of the wing well separated and well pushed under.

Samuel H. Scudder. 

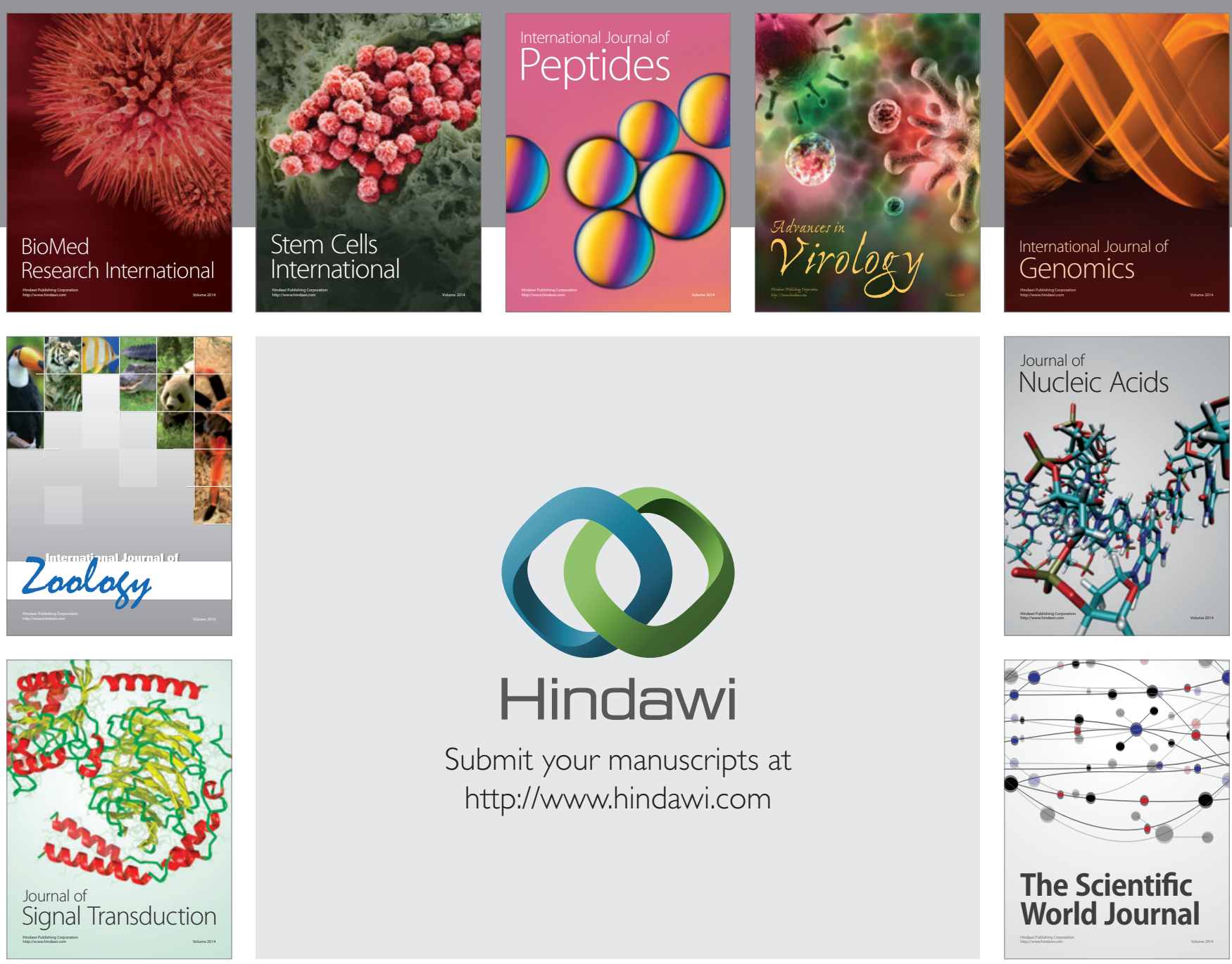

Submit your manuscripts at

http://www.hindawi.com
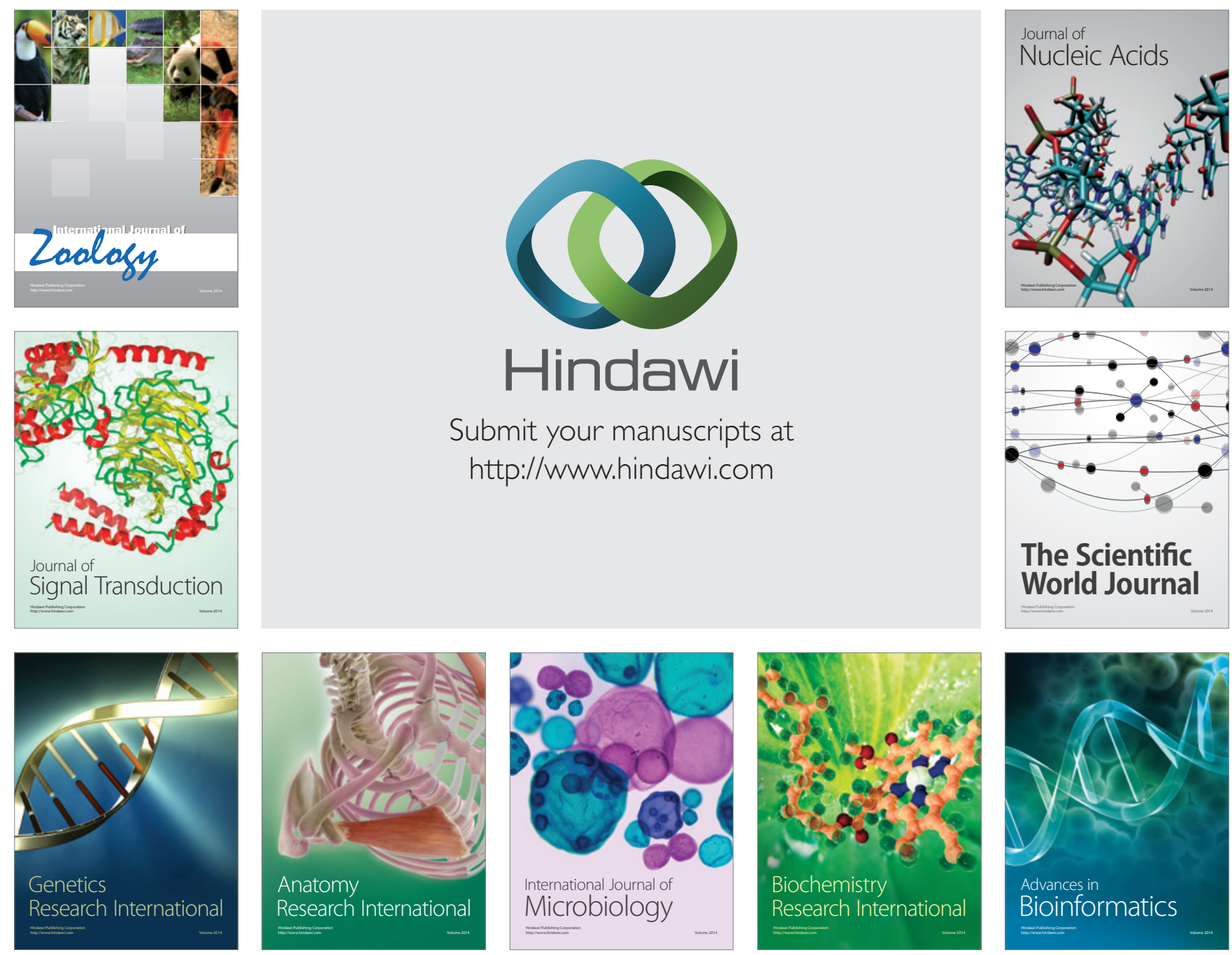

The Scientific World Journal
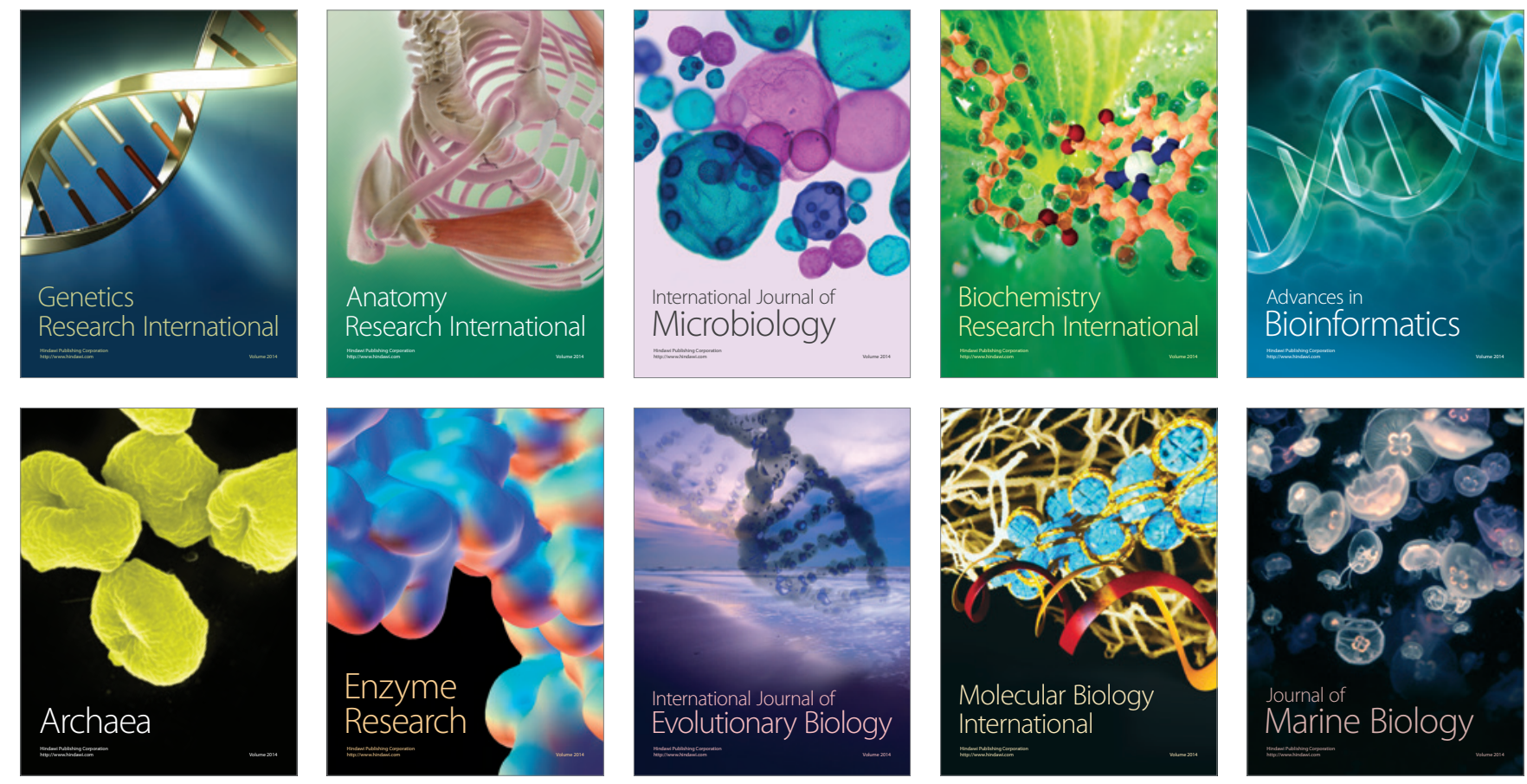